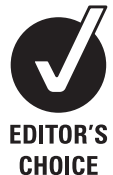

See Editorial, p 844

${ }^{1} \mathrm{MRC}$ Social and Public Health Sciences Unit, Glasgow, UK ${ }^{2}$ Cancer Control Research Program, Norris Cotton Cancer Center, Department of Pediatrics, Dartmouth Medical School, Lebanon, New Hampshire, USA

\section{Correspondence to}

Kate Hunt, MRC Social and Public Health Sciences Unit, 4 Lilybank Gardens, Glasgow, G12 8RZ Scotland, UK

k.hunt@sphsu.mrc.ac.uk

Received 27 February 2011 Accepted 26 May 2011 Published Online First 15 July 2011

\title{
Exposure to smoking in films and own smoking among Scottish adolescents: a cross-sectional study
}

\author{
Kate Hunt, ${ }^{1}$ Marion Henderson, ${ }^{1}$ Daniel Wight, ${ }^{1}$ James D Sargent ${ }^{2}$
}

ABSTRACT

Background Evidence of high exposure of UK youth to images of smoking in films has led to calls for an 18 rating for films with smoking to reduce smoking in youth. However, the only study to date in the UK to test for an association showed no relation between film-smoking exposure and smoking among young adults.

Objective To assess whether there is an association between exposure to film images of smoking and own smoking among UK adolescents and whether repeated viewings of films has an impact.

Design Cross-sectional study.

Participants 1999 pupils aged 15-16 years from 13 Scottish schools.

Outcome Smoked tobacco in the past year. Exposure measure Film-smoking exposure was assessed using the Beach method; account for repeated viewings of films was then used to modify estimated exposure. Covariates included: media usage, parental restriction on and context of TV/film viewing, family connectedness, parental monitoring and friends' smoking. Results Most $(71 \%)$ students had not smoked in the past year. About half reported no parental restrictions on TV/film viewing. Many reported repeated viewings of films; accounting for this more than doubled exposure estimates and strengthened the association with smoking. Adolescents with high exposure to film smoking were more likely to have smoked than those with low exposure (adjusted odds ratio (AOR) 2.08, 95\% Cl 1.22 to 3.55). Additionally, adolescents who reported parental rules about TV/film watching were less likely to smoke (AOR 0.37 (0.27 to 0.52)) than those who did not. Adolescents who mainly watched films with friends had higher exposure to film smoking and were more likely to smoke (AOR 2.19 (1.10 to 4.38)).

Conclusions Exposure to film smoking is associated with smoking among Scottish adolescents. These data lend support to calls for an 18 rating for films with images of smoking.

\section{INTRODUCTION}

In 2005, over 109000 UK deaths were attributed to smoking, costing the UK NHS an estimated $£ 5.2$ billion. $^{1}$ Smoking onset largely occurs during adolescence, ${ }^{2}$ and there is evidence that adolescents rapidly show signs of addiction after starting smoking. ${ }^{3}$ This underlines the importance of addressing factors that promote smoking uptake in adolescents, to minimise smoking onset.

Media portrayals are one potential influence shaping adolescents' views. With widespread restrictions on image advertising for cigarettes, smoking in films now rivals direct tobacco advertising "as the world's largest vector for sustaining the appeal of smoking" (p363). ${ }^{4}$ Portrayals of smokers in films largely ignore the negative consequences of smoking, ${ }^{5}$ seldom portray health costs ${ }^{6}$ and exaggerate levels of smoking by up to four times, ${ }^{7}$ contributing to heightened estimates of prevalence. $^{8}$

The US National Cancer Institute $(\mathrm{NCI})^{9}$ and the $\mathrm{WHO}^{10}$ have recognised the potential for film images of smoking to promote smoking to children and adolescents. The NCI concludes that the evidence points to a "causal relationship between exposure to depictions of smoking in movies and youth smoking initiation" (p12), and the WHO describes the "direct marketing of tobacco in the movies" as an "important vehicle for promoting smoking, including in films rated suitable for children and adolescents" (p1). An association between exposure to film smoking and smoking in adolescents (9-15 years) was first documented in the USA, in cross-sectional ${ }^{11} 12$ and prospective studies. ${ }^{13-15}$ Studies in Germany ${ }^{16-20}$ and Hong Kong ${ }^{21}$ report similar associations. Smoking depictions affect adolescent initiation whether the character smoking is a "good guy" or "bad guy". 7 A recent study found appearances of tobacco or tobaccorelated products in $70 \%$ of films distributed in the $\mathrm{UK}^{22}$ and in $68 \%$ of films judged by the British Board of Film Classification (BBFC) as suitable for children under 15 . An accompanying editorial ${ }^{23}$ called for a BBFC-18 rating for all film-smoking, with the exception of certain historical depictions.

However, the only study to test the hypothesis that viewing smoking in films is associated with own smoking among UK youth, to date, found no association among Scottish 19-year-olds. ${ }^{24}$ We report a study that tested the hypothesis among Scottish 15-16-year-olds. Our key research questions are: is there an independent relationship between exposure to film images of smoking and smoking in adolescents in the UK; is this affected by taking account of the number of times films are viewed and does the relation persist after accounting for covariates?

\section{METHODS}

Anonymous confidential questionnaires were completed by 1999 15-16-year-olds (88\% of eligible pupils) from 13 Scottish schools in 2007 in classrooms under exam conditions (researcher supervised with no teachers present), as part of the evaluation of a national sexual health demonstration project (Healthy Respect Phase 2; http://www.healthscotland.com/documents/4122. aspx). These schools had been preselected by the organisation conducting the sexual health intervention. All schools taking part in that intervention 
were included in the evaluation. The schools were selected to achieve a range in relation to social deprivation and rurality/ urbanicity. However, because all schools were non-denominational (because there were restrictions on the delivery of sex education in the Catholic schools in the selected educational authorities), the schools are not fully representative of all schools in Scotland. Informed consent was sought from parents and pupils; ethical permission was obtained from a Napier University Ethics Committee, in addition to permissions from the local education authorities and schools' senior management. No parent and five pupils refused participation.

\section{Key measures}

Outcome: smoking

Pupils were asked "In the last 12 months, how often have you smoked tobacco (cigarettes)?" (ever vs never in last year). Research shows that adolescents report smoking accurately in anonymous surveys. ${ }^{25}$

\section{Film-smoking exposure}

To estimate "film-smoking exposure", we used a modified version of the Beach method. ${ }^{11-13}$ Every pupil received a unique list of 50 films, randomly selected from a sample of 368 films (top 65 US box-office hits 2001-2005 $(n=325)$ and 43/50 top box-office hits for 2006). Details of smoking, including the number of occurrences (a character mentioning or handling a tobacco product), were coded in each film. Pupils indicated the number of times $(0,1,2,3,4-5,6+)$ they had seen each film to capture repeated viewing. We calculated two measures of exposure: the sum of the number of smoking occurrences in each film seen (Beach method) and the sum of the number seen, accounting for the number of viewings of that film ("Glasgow-modified Beach method"). We hypothesised that capturing repeat viewing exposure would result in a more reliable estimate of exposure, and the modified measure would be more strongly associated with adolescent smoking.

\section{Covariates}

Information was collected on variables that could be associated with smoking or film exposure, grouped into: media use/access, media rules, family background, individual characteristics and peer behaviours.

\section{Media use/access}

Exposure to smoking in films could be a proxy for high use of other entertainment media with smoking-related content. We assessed hours of television (TV)/DVD watching on weekdays, and bedroom access to TV, cable/satellite, and the internet. Greater TV time ${ }^{26}$ and bedroom TV $^{27}$ have been associated with higher risk for smoking.

\section{Media rules}

Parental restrictions on viewing adult-rated films have been linked with smoking. ${ }^{12} 17$ Four rules about TV/film use were combined into a standardised scale $(\alpha=0.64$, higher values indicating greater restriction). Internet supervision was assessed similarly, but with only two items that were not highly correlated and so were modelled separately.

The context of viewing may affect responses. We hypothesised that adolescents who mainly watch TV/DVDs with parents would have a blunted response to film-smoking and lower risk for smoking because smoking would be interpreted in the context of parental presence.

\section{Family background}

We assessed housing tenure and parental education as measures of socioeconomic status (SES) (table 1), as low SES is associated with higher media usage and smoking in adolescence. Poorer family functioning is also linked with smoking. ${ }^{28}$ Pupils' ratings of family connectedness $(\alpha=0.76)$ and parental monitoring $(\alpha=0.71)$ were based on responses to seven and six items, respectively (table 1).

\section{Individual characteristics}

We anticipated gender differences in media use (eg, in films that boys and girls viewed repeatedly); smoking also differed by gender in this sample. Because pupils less involved in school have more time for media viewing and are more likely to smoke, we assessed number of national examinations being sat and school leaving plans (table 1).

\section{Peer behaviours}

Peer smoking is a strong risk factor for smoking in cross-sectional studies. Pupils estimated the number of friends who smoke. We hypothesised that adolescents who mainly watch with friends (two-item scale with separate questions for same vs mixed-sex friends, $\alpha=0.78$ ) would be at higher risk for smoking because interpretations of film smoking would be made in the friend context.

\section{Analysis}

Descriptive statistics were examined. Prior to variable re-scaling, we assessed two-way relationships between each predictor variable and smoking. To simplify multivariate analyses, any variable not associated with smoking in the two-way analysis (at $\mathrm{p}<0.05$ ) was omitted from further analysis.

The OR was the measure of association. Ordinal and continuous variables were rescaled so that a one-point increase represented going from lowest to highest exposure. As an example, family connectedness ranged from 0 (low connectedness) to 8 . This variable was divided by 8 so that the rescaled variable ranged from 0 to 1 and modelled the association with smoking for highest versus lowest levels of connectedness. Continuous variables were treated similarly. Film-smoking exposure was skewed left; to minimise influence of high outliers, values over the 95th percentile for that variable were first set to the 95th percentile before rescaling (which involved dividing the variable by the film exposure level corresponding to the 95th percentile).

Multivariate logistic models were built sequentially. First, the relationship between film-smoking exposure and youth smoking was assessed in two-way analyses using the Beach exposure and Glasgow-modified Beach exposure, to assess which was more strongly associated with smoking. Subsequent models using the Glasgow-modified exposure made additional adjustment for media rules, then also family background and then individual characteristics; the final model controlled additionally for peer behaviours. The stepwise inclusion of variables allowed an examination of whether groups of variables confounded the association between film-smoking exposure and youth smoking.

Sensitivity analyses tested whether the results for the final model were substantially altered by how film-smoking exposure was modelled or how covariates were entered. We re-estimated this model with all pertinent covariates but with the following alternative ways of entering film smoking: continuous variable scaled from 0 to 1 but without trimming outliers, scaled so that median exposure was one (with and without trimming outliers), with film exposure modelled as a set of dummy variables 
Table 1 Description of the sample and crude associations with smoking

\begin{tabular}{|c|c|c|c|c|}
\hline \multirow[b]{2}{*}{$\begin{array}{l}\text { Continuous variables } \\
\text { Categorical variables }\end{array}$} & \multirow[b]{2}{*}{$\begin{array}{l}\text { Median } \\
\text { n }\end{array}$} & \multirow[b]{2}{*}{$\begin{array}{l}\operatorname{IOR}_{\%}^{*} \\
\%\end{array}$} & \multicolumn{2}{|c|}{$\begin{array}{l}\text { Association with } \\
\text { smoking } \dagger\end{array}$} \\
\hline & & & $\begin{array}{l}\text { Crude } \\
\text { OR }\end{array}$ & p Value \\
\hline \multicolumn{5}{|l|}{ Smoking status } \\
\hline Never smoked in last year & 1406 & 71.1 & & \\
\hline Ever smoked in last year & 572 & 28.9 & & \\
\hline Missing & 21 & & & \\
\hline \multicolumn{5}{|l|}{ Film-smoking exposure } \\
\hline Beach method (does not consider times seen) & 96 & $60-134$ & 2.08 & 0.001 \\
\hline Modified Beach method (considers times seen) & 196 & $120-314$ & 2.59 & $<0.0001$ \\
\hline \multicolumn{5}{|l|}{ Media use/access } \\
\hline \multicolumn{5}{|l|}{ Number of hours watching TV/DVDs on weekdays } \\
\hline Quartile $1(0-2 \mathrm{~h})$ & 610 & 30.5 & Ref & \\
\hline Quartile 2 (3 h) & 321 & 16.1 & 1.07 & 0.67 \\
\hline Quartile $3(4-5 \mathrm{~h})$ & 389 & 19.5 & 1.31 & 0.09 \\
\hline Quartile 4 ( 6 or more hours) & 460 & 23.0 & 1.32 & 0.62 \\
\hline Missing & 219 & 11.0 & 1.14 & 0.49 \\
\hline \multicolumn{5}{|l|}{ Has DVD or video player in bedroom } \\
\hline Yes & 1798 & 89.9 & Ref & \\
\hline No & 155 & 7.8 & 0.75 & 0.46 \\
\hline Missing & 46 & 2.3 & & \\
\hline \multicolumn{5}{|l|}{ Has access to the internet/web in bedroom } \\
\hline Yes & 1061 & 53.1 & & \\
\hline No & 787 & 39.4 & 0.64 & 0.06 \\
\hline Missing & 151 & 7.6 & & \\
\hline \multicolumn{5}{|l|}{ Has digital, satellite or cable TV channels } \\
\hline Yes & 1307 & 65.4 & & \\
\hline No & 599 & 30 & 1.02 & 0.86 \\
\hline Missing & 93 & 4.7 & & \\
\hline \multicolumn{5}{|l|}{ Rules about media } \\
\hline \multicolumn{5}{|l|}{ Television/films rules } \\
\hline \multicolumn{5}{|l|}{ Parental approval of what is watched: } \\
\hline Definitely not/possibly not & 285 & 14.5 & Ref & \\
\hline Don't know & 345 & 17.6 & 1.17 & 0.29 \\
\hline They wouldn't mind & 944 & 48 & 1.06 & 0.75 \\
\hline They would approve & 391 & 19.9 & 1.09 & 0.66 \\
\hline Missing & 34 & & & \\
\hline \multicolumn{5}{|l|}{ Allowed to watch 18 certificate films } \\
\hline Yes & 1852 & 92.6 & Ref & \\
\hline No & 147 & 7.4 & 0.19 & $<0.0001$ \\
\hline \multicolumn{5}{|l|}{ Has to finish homework/chores before watching TV } \\
\hline No & 1655 & 82.8 & Ref & \\
\hline Yes & 344 & 17.2 & 0.4 & $<0.0001$ \\
\hline \multicolumn{5}{|l|}{ Only allowed to watch a certain amount of TV } \\
\hline No & 1915 & 95.8 & Ref & \\
\hline Yes & 84 & 4.2 & 0.37 & 0.006 \\
\hline Access to some TV programs restricted & & & & \\
\hline No & 1523 & 92.5 & Ref & \\
\hline Yes & 123 & 7.5 & 0.17 & $<0.0001$ \\
\hline Allowed to watch anything on TV & & & & \\
\hline Yes & 1586 & 79.3 & Ref & \\
\hline No & 413 & 20.7 & 0.20 & $<0.0001$ \\
\hline Breaks TV/DVD rules: & & & & \\
\hline Assume don't have rules about watching TV & 905 & 47.9 & Ref & \\
\hline Yes, I often break them & 163 & 8.6 & 1.13 & 0.51 \\
\hline Yes, I sometimes break them & 443 & 23.5 & 0.3 & $<0.0001$ \\
\hline No, I follow these rules & 377 & 20 & 0.39 & $<0.0001$ \\
\hline Missing & 111 & & & \\
\hline $\begin{array}{l}\text { TV/films parenting scale from above six variables }(\alpha=0.68) \\
(0-6) \text { each one point increase is adding an item }\end{array}$ & 1 & $0-3$ & 0.71 & $<0.0001$ \\
\hline Film viewing pattern & & & & \\
\hline Views films with parents $(0-4)$ & 2 & $1-3$ & & 0.43 \\
\hline
\end{tabular}


Table 1 Continued

\begin{tabular}{|c|c|c|c|c|}
\hline \multirow[b]{2}{*}{$\begin{array}{l}\text { Continuous variables } \\
\text { Categorical variables }\end{array}$} & \multirow[b]{2}{*}{$\begin{array}{l}\text { Median } \\
\mathrm{n}\end{array}$} & \multirow[b]{2}{*}{$\begin{array}{l}\operatorname{IOR}^{*} \\
\%\end{array}$} & \multicolumn{2}{|c|}{$\begin{array}{l}\text { Association with } \\
\text { smoking } \dagger\end{array}$} \\
\hline & & & $\begin{array}{l}\text { Crude } \\
\text { OR }\end{array}$ & p Value \\
\hline \multicolumn{5}{|l|}{ Internet rules } \\
\hline \multicolumn{5}{|l|}{ Internet access restricted or not } \\
\hline Yes & 327 & 16.5 & Ref & \\
\hline No & 1317 & 66.4 & 0.79 & 0.125 \\
\hline Don't know & 339 & 17.1 & & \\
\hline Missing & 16 & & & \\
\hline \multicolumn{5}{|l|}{ Internet usage supervised? } \\
\hline No & 1431 & 0.72 & Ref & \\
\hline Yes & 216 & 0.11 & 0.67 & 0.025 \\
\hline Missing & 352 & 0.21 & & \\
\hline \multicolumn{5}{|l|}{ Family background } \\
\hline \multicolumn{5}{|l|}{ Housing tenure } \\
\hline Owner-occupied & 1453 & 20.8 & Ref & \\
\hline All other types of accommodation & 416 & 72.7 & 1.46 & 0.005 \\
\hline Missing & 130 & 6.5 & & \\
\hline \multicolumn{5}{|l|}{ Parental education: } \\
\hline Either/only parent remained at school beyond age 16 & 961 & 48.1 & Ref & \\
\hline Both/only parent(s) left school at 16 years of age & 671 & 33.6 & 1.52 & 0.001 \\
\hline Missing & 367 & 18.4 & & \\
\hline Family connectedness: $(0-8)$ & 6 & $5-7$ & 0.35 & $<0.0001$ \\
\hline Parental monitoring: $(0-8)$ & 6 & $4-7$ & 0.46 & $<0.0001$ \\
\hline \multicolumn{5}{|l|}{ Individual characteristics } \\
\hline \multicolumn{5}{|l|}{ Gender } \\
\hline Male & 1008 & 50.6 & Ref & \\
\hline Female & 984 & 49.4 & 1.82 & $<0.0001$ \\
\hline Missing & 7 & & & \\
\hline \multicolumn{5}{|l|}{ Number of national school examinations being sat } \\
\hline $7+$ & 1008 & 50.4 & Ref & \\
\hline 6 or less & 802 & 40.1 & 1.78 & $<0.0001$ \\
\hline Missing & 189 & 9.5 & 2.31 & $<0.0001$ \\
\hline \multicolumn{5}{|l|}{ School leaving plans } \\
\hline Plans to remain in school beyond statutory leaving age & 1350 & 69.3 & Ref & \\
\hline Plans to leave school as soon as legally entitled to & 363 & 18.7 & 3.59 & $<0.0001$ \\
\hline Don't know & 233 & 12 & 1.28 & 0.17 \\
\hline Missing & 53 & & & \\
\hline \multicolumn{5}{|l|}{ Peer behaviours } \\
\hline Peer smoking ( 0 none, 4 most/all) & 1 & $2-2$ & 51.7 & $<0.0001$ \\
\hline Views movies with friends & 2 & $1-2$ & 3.85 & $<0.0001$ \\
\hline
\end{tabular}

representing higher quartiles of exposure and as a dichotomous variable split at the median. Alternate covariate patterns included adding all variables that were not significantly associated with smoking and modelling other continuous covariates as dichotomous variables using a median split.

Finally, two covariates were thought to be part of the causal pathway from higher film exposure to adolescent smoking; hence, their inclusion would overspecify the model resulting in an underestimation of the association between film smoking and adolescent smoking. Parental R-rated film restrictions have been shown to reduce exposure to film smoking and therefore represent a distal variable on the causal pathway: parental film restriction $\rightarrow$ film-smoking exposure $\rightarrow$ adolescent smoking. It is plausible that friends could initiate smoking as a result of shared film exposures and become a proximal risk factor for the adolescent in the causal pathway: film-smoking exposure $\rightarrow$ friend smoking $\rightarrow$ adolescent smoking. The sensitivity analysis explored how removal of these covariates affected estimates for film-smoking exposure.

\section{RESULTS}

Table 1 provides descriptive statistics for all variables for the 1999 pupils. Eighty-six percent completed the media exposure questions. Most lived in owner-occupied homes, but only half had parents who remained at school beyond age 16 . The majority (71\%) had not smoked in the last year, $37 \%$ had no friends that smoked and $12 \%$ reported that most or all friends smoked.

The media exposure questions came at the end of a long questionnaire. This ordering meant that less academically able pupils who were unable to complete the questionnaire within the allocated lesson had missing data on the media exposure questions. Forty-six per cent of those with missing data on these questions were below average in the number of examinations they were sitting versus $30 \%$ of those with no missing data $(p<0.000)$. Similarly, $47 \%$ with missing data wanted to leave school at the earliest legal age compared to $17 \%$ of those with no missing data $(\mathrm{p}<0.000)$

Many adolescents reported repeatedly viewing films. Accounting for the number of times adolescents had seen each 
film more than doubled film-smoking exposure (median exposure Glasgow-modified Beach method=196 smoking episodes, IOR 120-314; median exposure Beach method 96 smoking episodes, IOR 60-134); correlation between the two measures was 0.80 . The 95 th percentile for the Glasgow-modified measure was almost three times as high as the 95th percentile for the Beach exposure measure (564 vs 209). There was also much TV exposure, with $23 \%$ reporting viewing $6+\mathrm{h}$ /day and most having bedroom access to cable TV. Few reported parental TV/ film or internet restrictions; for example, about half reported no restriction on their $\mathrm{TV} /$ film viewing.

Table 1 also shows two-way associations between predictor variables and smoking last year. A striking association was the lower risk associated with greater parental TV/film restriction, as illustrated in figure 1 , which presents the crude dose-response of smoking in relation to (a) greater parental TV/ film restriction and (b) higher film-smoking exposure. Adolescents with low and high film-smoking exposure have prevalences of smoking of $15 \%$ and $37 \%$, respectively. Adolescents with few parental TV/film restrictions smoke at rates comparable to adolescents with high film-smoking exposure, whereas smoking among those reporting many restrictions is negligible. As expected, those reporting that all/most of their friends smoked were more likely to be smokers (table 1).

Table 2 reports the multivariate models. Model 1 shows that the two-way association was stronger for the Glasgow-modified Beach exposure, which accounted for multiple viewings of films; the modified exposure variable was used in all subsequent analyses. Adjusting for parental media use rules attenuated the association between film-smoking exposure and adolescent smoking somewhat, as did adding family characteristics. The association OR increased considerably however, from 2.39 to 3.10 , with the addition of individual characteristics. Finally, there was substantial attenuation with the addition of friend environment predictors; in the final model, adolescents with high film-smoking exposure had more than twice the odds of smoking (adjusted odds ratio (AOR) 2.08 (95\% CI 1.22 to 3.55)) compared to those with low exposure. Other variables were associated with smoking. Adolescents who reported rules about TV/film watching had a lower odds of smoking (AOR 0.37 (0.27 to 0.52)); higher family connectedness also contributed to lower smoking risk but not (in the fully adjusted model) higher parental monitoring about things other than media use. Film viewing pattern also seemed important, especially when adolescents mostly watched films with friends (AOR 2.19 (1.10 to 4.38)). Thus, watching films with friends conferred additional risk in the same range as high film-smoking exposure. Watching mostly with parents was protective to about the same degree (although not statistically significant in the final model). Girls were more likely than boys to smoke (OR 2.26 (1.68 to 3.02$)$ ), as were those performing poorly in school or planning to leave school as soon as they were legally able. Finally, peer smoking was strongly associated with smoking, as often shown previously.

Table 3 reports the sensitivity analyses. Changing the way film-smoking exposure was modelled affected the estimate size but not the general conclusion. Outlier trimming tended to increase the size because outliers reported much higher film smoking but not much higher smoking. When modelling exposure in quartiles, only quartile 4 had significantly higher odds of smoking (AOR 1.49 (1.00 to 2.22)) than quartile 1, a similar effect estimate as obtained when modelling exposure as a dichotomous variable using a median split.

The estimate of the association between film smoking and adolescent smoking was little affected by adding all the variables

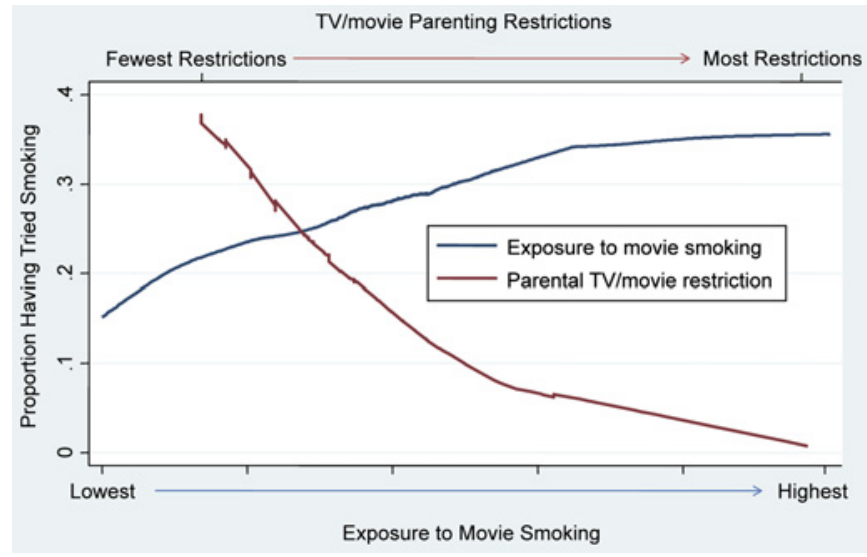

Figure 1 Lowess plot comparing the crude dose-response to higher exposure to film smoking with greater parental TV/film restrictions. Approximately $15 \%$ of adolescents with lowest exposure to film-smoking have tried smoking compared with $33 \%$ for those with highest exposure levels. Approximately $38 \%$ of adolescents reporting no parental TV/film restrictions have tried smoking (these adolescents represent about half of adolescents in the sample), whereas almost none with multiple restrictions have tried smoking.

in table 1, which were not significantly associated with adolescent smoking. The estimate was strengthened somewhat when modelling using the median split when other continuous covariates were modelled in the same way. Finally, removing two theoretical mediating pathway variables substantially strengthened the association, increasing the estimate from 2.08 to 2.63 when modelled as a trimmed continuous variable and from 1.49 to 1.91 when comparing quartile 4 with quartile 1 exposure.

\section{DISCUSSION}

This study, like other cross-sectional ${ }^{11} 12161829$ and longitudinal studies $^{13} 141718$ in the USA and Germany, shows an independent association between estimates of exposure to film images of smoking and smoking in 15-16-year-old adolescents in Scotland. The magnitude of the risk observed here is similar to other cross-sectional studies of adolescents in this age range. The findings contrast with the only published UK study on this topic, ${ }^{24}$ which found no association between film-smoking exposure and young people's smoking, among an older study population (aged 19). That study raised the possibility that concerns about exposure to smoking in films among UK youth ${ }^{23}$ were not empirically justified. The current results suggest that they are and that young UK adolescents respond in much the same way to films as adolescents in other countries. We believe that the difference between the findings of these two UK studies is accounted for by methodological limitations in the earlier study and the fact that most were established daily smokers, for whom nicotine addiction is a more important component of their smoking. ${ }^{24}$ Recent studies confirm that the effect of exposure to film smoking is stronger for smoking onset than for progression from onset to established smoking. ${ }^{30} 31$ Other research suggests that symptoms of tobacco addiction appear early in the course of adolescent smoking ${ }^{3}$ and outweigh other influences in compelling adolescents to continue smoking. As two-thirds of the young adults in the earlier Scottish study were established smokers, it may not be surprising that no association was found.

To date, no other studies have considered repeated film viewings in assessments of exposure; this study suggests they should, since repeated viewings may account for upwards of half 


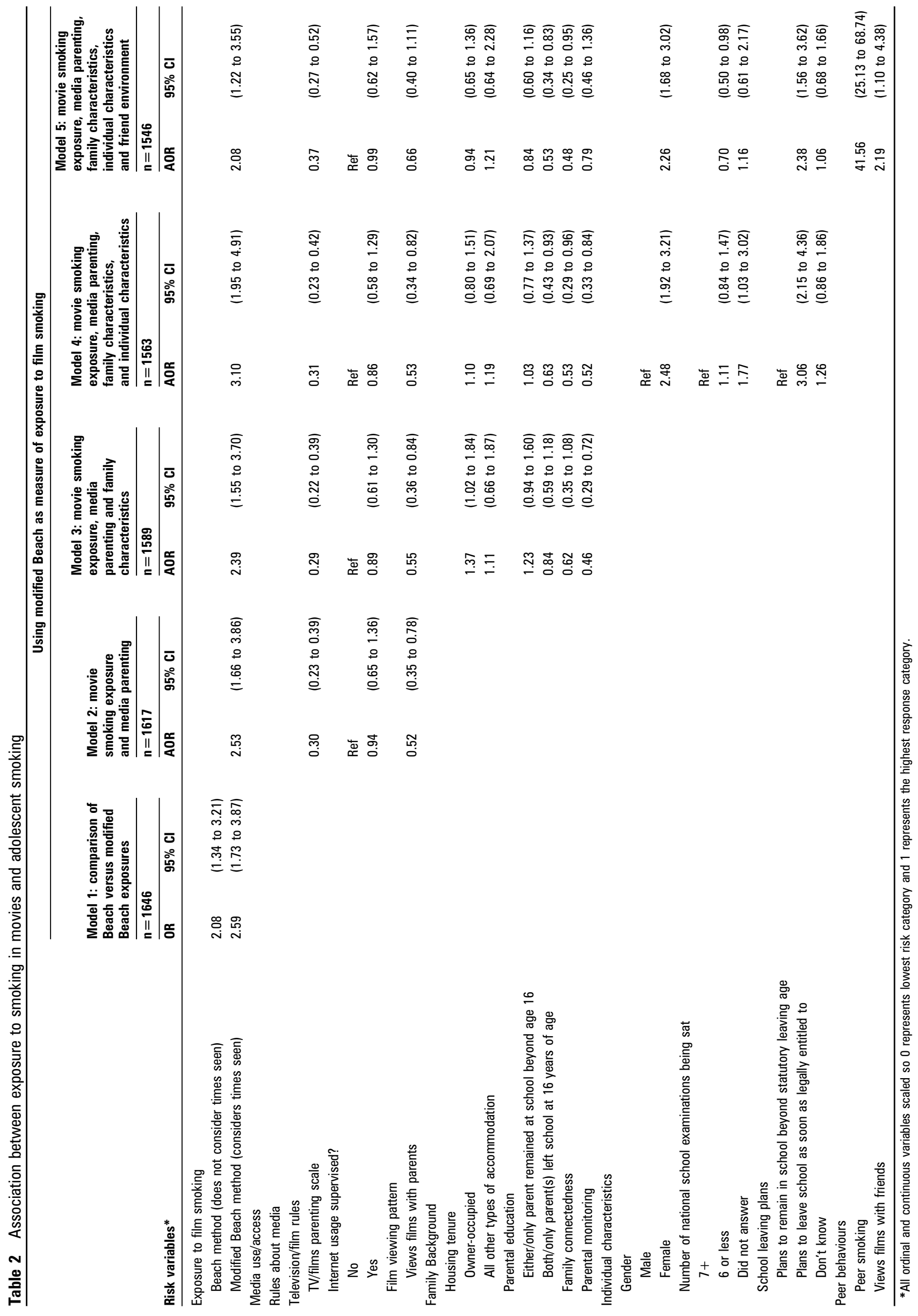

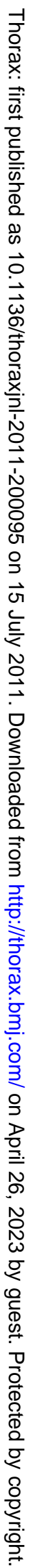


Table 3 Sensitivity analysis

\begin{tabular}{|c|c|c|c|}
\hline \multicolumn{4}{|c|}{ Sensitivity to the covariates included and how they are modelled } \\
\hline $\begin{array}{l}\text { Model 1: covariate } \\
\text { adjustment equivalent } \\
\text { to model } 5 \text {, table } 2\end{array}$ & $\begin{array}{l}\text { Model 2: all non- } \\
\text { significant covariates } \\
\text { in table } 1 \text { added to } \\
\text { model } 1\end{array}$ & $\begin{array}{l}\text { Model 3: all continuous } \\
\text { covariates in model } 1 \\
\text { dichotomised at } \\
\text { median split }\end{array}$ & $\begin{array}{l}\text { Model 4: removal of } 2 \\
\text { plausible mediators - media } \\
\text { parenting and friend } \\
\text { smoking - from model } 1\end{array}$ \\
\hline$n=1546$ & $n=1532$ & $n=1546$ & $n=1554$ \\
\hline $95 \% \mathrm{Cl}$ & $95 \% \mathrm{Cl}$ & $95 \% \mathrm{Cl}$ & $95 \% \mathrm{Cl}$ \\
\hline
\end{tabular}

\begin{tabular}{|c|c|c|c|c|c|c|c|c|}
\hline \multicolumn{8}{|c|}{ Sensitivity to how film-smoking exposure is modelled } & Exposure to film smoking \\
\hline \multicolumn{9}{|l|}{ Scaled so lowest is 0 and highest is 1} \\
\hline No outlier trimming & 2.95 & (1.37 to 6.36$)$ & & & & & & \\
\hline \multicolumn{9}{|l|}{ Scaled so that median value is 1} \\
\hline No outlier trimming & 1.25 & (1.07 to 1.47$)$ & & & & & & \\
\hline \multicolumn{9}{|l|}{ Modelled as dummy variables } \\
\hline \multicolumn{9}{|l|}{ Quartiles of exposure } \\
\hline Quartile 1 & Ref & & & & & & Ref & \\
\hline Quartile 2 & 0.91 & (0.60 to 1.37$)$ & & & & & 1.10 & (0.78 to 1.58$)$ \\
\hline Quartile 3 & 1.25 & (0.83 to 1.88$)$ & & & & & 1.45 & (1.02 to 1.06$)$ \\
\hline
\end{tabular}

of exposure. A plausible explanation for the strengthening of the association when repeated viewing is considered is that it constitutes a more reliable measure of exposure. Additionally, adolescents will choose to review films they most like, and repeated viewing may therefore reinforce the impact of personally appealing smoking images within films. Others have commented on the "long shelf life that movies gain through television rebroadcast, videotape, and DVD" (p262), ${ }^{32}$ shaping how film images of smoking are increasingly experienced. Films are becoming increasingly accessible through downloads to personal computers and mobile phones and the proliferation of satellite and digital channels rebroadcasting popular films. As this trend continues, repeated viewings may become an even larger share of adolescent media viewing. However, it should be acknowledged that there may be some recall bias in the number of times that a film has been viewed, and some repeated film reviewings may be partial.

Limiting access to television shows and films rated for adults may be an approach for parents to consider. This study replicates the finding that parental media restriction is uncommon but inversely related to smoking risk. Longitudinal studies from multiple countries now offer robust evidence that such restrictions prevent the onset of tobacco and alcohol use. ${ }^{12} 173334$ The association observed in this sample deserves further investigation to see whether the development of interventions to limit exposure of children/young adolescents to entertainment media depicting adult smoking and drinking to prevent these behaviours is worthwhile and confirm independent associations from observational studies.

Another new finding here is that the context in which adolescents watch films may affect their likelihood of smoking. Adolescents who watched TV/films with friends had a higher risk for smoking, independent of their film-smoking exposure. Adolescents who watched TV/films with parents had a lower risk, although this association was not as robust as the one with friends. We tested for an interaction between these variables and film-smoking exposure and found none, so it does not appear that context influences the dose-response to film smoking. However, those who mainly viewed with friends tended to have a higher dose of film-smoking exposure. Perhaps viewing films mainly with friends identifies adolescents who are particularly peer-orientated, spending more time in social contexts that include offers and opportunities to smoke.

Our findings are limited by our inability to determine whether film exposure preceded smoking onset because of the crosssectional nature of the design. However, longitudinal studies suggest that film-smoking exposure in never-smoker adolescents predicts future onset. As with any observational study, the results may be affected by failure to control for unmeasured confounders, notably parent smoking and adolescents' risktaking propensity. Previous studies ${ }^{11-20}$ that controlled for these two variables have obtained similarly sized estimates of the film smoking-adolescent smoking association. Finally, many pupils with poor reading skills were unable to complete the questionnaire in the allotted time and therefore did not complete the questions about films watched; our results may not be generalisable to these adolescents.

Despite these limitations, this study adds to evidence from studies in multiple countries that support efforts to minimise depictions of smoking in films intended for children and adolescents. With regulations all but eliminating image advertising for smoking, entertainment images of smoking remain the main media source of such imagery. The UK Department of Health $^{35}$ has already acknowledged that it should work with the BBFC to follow through on the advice of its own communications regulator, Ofcom, which has established clear guidelines about smoking images in the media. These state that smoking: "must not be featured in programs made primarily for children (under 15 years of age) unless there is strong editorial justification" and "must not be condoned, encouraged or glamorised in 


\section{What is already known on this topic}

- Cross-sectional and longitudinal studies from USA and other countries have shown an association between exposure to images of smoking in films and young adolescents' own smoking behaviours. However, one cross-sectional study of 19-year-olds in Scotland found no such association. Yet, high exposure to smoking in films has been documented among UK adolescents, prompting a call for an 18 rating for films with smoking.
Funding The external evaluation of Healthy Respect 2 was funded by NHS Health Scotland. The role of this funder was to ensure that deadlines were met, to publish the Final Report, to support the dissemination of results, and to help translate results into policy and practice. KH, DW and MH are employed by the UK Medical Research Council (MC US A540 0036; MC US A540 0046). JS received funding from National Institutes of Health (CA07026, PI James Sargent)

\section{Competing interests None.}

Patient consent All participating pupils provided written informed consent to the study. In addition, parental opt out consent was obtained from parents.

Contributors All authors contributed to the design, analytical approach, interpretation and write-up of results. $\mathrm{MH}$ and JS undertook the analyses. MH, DW and $\mathrm{KH}$ contributed to the design of the questionnaires used. MH oversaw all stages of the data collection, data preparation and data entry.

Provenance and peer review Not commissioned; externally peer reviewed.

\section{REFERENCES}

1. Allender S, Balakrishnan R, Scarborough P, et al. The burden of smoking-related illhealth in the UK. Tob Control 2009;18:262-7.

- This study of younger Scottish adolescents (aged $15-16$ years) shows an association between exposure to images of smoking in films and own smoking similar to studies in USA and Germany.

- This study extends previous work by showing a dose effect: accounting for the number of times each adolescent had seen each film doubles exposure estimates and strengthens the association with their smoking. This study also found that parental restrictions on television and film viewing, although uncommon, were strongly protective, independent of filmsmoking exposure and parenting generally. Finally, film viewing environment may matter: adolescents who view films with parents tend to have lower risk for smoking, whereas those that view films with friends have higher risk.

other programs likely to be widely seen or heard by undereighteens unless there is editorial justification". This is inadequate when one considers that 15 years is when some of the highest rates of smoking onset occur in UK adolescents. Our findings add to the weight of the evidence for a BBFC-18 rating for film smoking, which would limit young adolescents' exposure to all but historical images of smoking, thus minimising their exposure to glamourised images at an age when adolescents appear vulnerable to acting on them by trying smoking. The viewing by children and adolescents of age-appropriate films as defined by country-specific guidelines exposes UK adolescents to more "tobacco impressions" than their peers in the USA; 79\% of films that attract an $\mathrm{R}$ (adult) rating in the USA have a "15" or " $12 \mathrm{~A}$ " rating in the UK. ${ }^{36}$ A change to the ratings systems that requires all youth-rated movies to be smoke free could result in a substantial public health gain, given the difficulty adolescents have in quitting smoking once they begin and the enormous health consequences of continued smoking. However, once implemented, future research should ensure that there are no unintended consequences of the legislation, such as reduced parental concern to enforce this rating, increased social inequalities in exposure to smoking images and increased attractiveness of such films to rebellious teenagers. These results also lend weight to activities that aim to support parents in implementing media restrictions during childhood and early adolescence. $^{37}$

Acknowledgements The authors would like to thank the staff and pupils in participating schools, the survey staff, and other colleagues who contributed to the Evaluation of Healthy Respect. KH, MH and DW are employed by the UK Medical Research Council (MC US A540 0036; MC US A540 0046). JS would like to acknowledge support from the NïH (NIH CA0̄7026).
2. Lynch B, Bonnie R. Growing Up Tobacco Free-Preventing Nicotine Addiction in Children and Youths: A Report of the Institute of Medicine. Washington, DC: National Academy Press, 1994.

3. DiFranza JR, Savageau JA, Fletcher K, et al. Symptoms of tobacco dependence after brief intermittent use: the Development and Assessment of Nicotine Dependence in Youth-2 study. Arch Pediatr Adolesc Med 2007;161:704-10.

4. Chapman S. What should be done about smoking in movies? Tob Control 2008;17:363-7.

5. Stockwell TF, Glantz SA. Tobacco use is increasing in popular films. Tob Control 1997;6:282-4

6. Dozier DM, Lauzen MM, Day CA, et al. Leaders and elite: portrayals of smoking in popular films. Tob Control 2005;14:7-9.

7. Tanski S, Stoolmiller M, Dal Cin S, et al. Movie character smoking and adolescent smoking: who matters more, good guys or bad guys? Pediatrics 2009;124:135-43.

8. Charlesworth A, Glantz SA. Smoking in the movies increases adolescent smoking: a review. Pediatrics 2005;116:1516-28.

9. Davis RM, Gilpin EA, Loken B, et al, eds. The Role of the Media in Promoting and Reducing Tobacco Use. Bethesda, MD: US Department of Health and Human Service, National Institutes of Health, National Cancer Institute, 2008.

10. World Health Organisation. Smoke-Free Movies: From Evidence to Action. Geneva: Tobacco Free Initiative, World Health Organization, 2009.

11. Sargent JD, Beach ML, Dalton MA et al. Effect of seeing tobacco use in films on trying smoking among adolescents: cross sectional study. BMJ 2001;323:1-6.

12. Sargent JD, Beach ML, Dalton MA, et al. Effect of parental R-rated movie restriction on adolescent smoking initiation. Pediatrics 2004;114:149-56.

13. Dalton MA, Sargent JD, Beach ML, et al. Effect of viewing smoking in movies on adolescent smoking initiation: a cohort study. Lancet 2003;362:281-5.

14. Distefan JM, Pierce JP, Gilpin EA. Do favorite movie stars influence adolescent smoking initiation? Am J Public Health 2004;94:1239-44.

15. Titus-Ernstoff $\mathbf{L}$, Dalton MA, Adachi-Mejia AM, et al. Longitudinal study of viewing smoking in movies and initiation of smoking by children. Pediatrics 2008;121:15-21.

16. Hanewinkel R, Sargent JD. Exposure to smoking in popular contemporary movies restriction on teen smoking and drinking in Germany. Addiction 2008;103:1722-30.

18. Hanewinkel R, Sargent JD. Exposure to smoking in internationally distributed American movies and youth smoking in Germany: a cross-cultural cohort study. Pediatrics 2008;121:108-17.

19. Hanewinkel R, Tanski SE, Sargent JD. Exposure to alcohol use in motion pictures and teen drinking in Germany. Int J Epidemiol 2007:36:1068-77.

20. Hastings G, Angus K. Forever Cool: The Influence of Smoking Imagery on Young People. London: British Medical Association, 2008.

21. BMA Board of Science. Forever Cool: The Influence of Smoking Imagery on Young People. London: British Medical Association, 2008.

22. Lyons $\mathbf{A}$, McNeill $A$, Chen $Y$, et al. Tobacco and tobacco branding in films most popular in the UK from 1980 to 2008. Thorax 2010;65:417-22.

23. Millett C, Glantz SA. Assigning an ' 18 ' rating to movies with tobacco imagery is essential to reduce youth smoking. Thorax 2010;65:377-8.

24. Hunt K, Sweeting H, Sargent J, et al. An examination of the association between seeing smoking in films and tobacco use in young adults in the west of Scotland: cross sectional study. Health Educ Res 2009;24:22-31.

25. Murray DM, Perry CL. The measurement of substance use among adolescents: when is the 'bogus pipeline' method needed? Addict Behav 1987;12:225-33.

26. Gidwani $\mathbf{P}$, Sobol A, DeJong W, et al. Television viewing and initiation of smoking among youth. Pediatrics 2002;110:505-8.

27. Jackson C, Brown JD, L'Engle KL. R-rated movies, bedroom televisions, and initiation of smoking by white and black adolescents. Arch Pediatr Adolesc Med 2007;161:260-8 and youth smoking in Germany. Am J Prev Med 2007;32:466-73.

17. Hanewinkel R, Morgenstern M, Tanski SE, et al. Longitudinal study of parental movie 
28. Jackson C, Bee-Gates DJ, Henriksen L. Authoritative parenting, child competencies, and initiation of cigarette smoking. Health Educ 0 1994;21:103-16.

29. Sargent JD, Beach ML, Adachi-Mejia AM, et al. Exposure to movie smoking: its relation to smoking initiation among U.S. adolescents. Pediatrics 2005;116:1183-91.

30. Sargent JD, Gibson J, Heatherton TF. Comparing the effects of entertainment media and tobacco marketing on youth smoking. Tob Control 2009;18:47-53.

31. Sargent JD, Hanewinkel R. Comparing the effects of entertainment media and tobacco marketing on youth smoking in Germany. Addiction 2009;104:815-23.

32. Glantz SA, Kacirk KW, McCulloch C. Back to the future: smoking in movies in 2002 compared with 1950 levels. Am J Public Health 2004;94:261-3.
33. Dalton MA, Adachi-Mejia AM, Longacre MR, et al. Parental rules and monitoring of children's movie viewing association with children's risk for smoking and drinking. Pediatrics 2006;118:1932-42.

34. de Leeuw RN, Sargent JD, Stoolmiller M, et al. Association of smoking onset with the R-rated movie restrictions and adolescent sensation seeking. Pediatrics 2011;127:e96-105

35. Department of Health. A Smokefree Future. A Comprehensive Tobacco Control Strategy for England. London: HM Government, 2010.

36. Anderson SJ, Millett C, Polansky JR, et al. Exposure to smoking in movies among British adolescents 2001-2006. Tob Control 2010;19:197-200.

37. Sargent JD. Getting a handle on the media: where should we focus our efforts? Acad Pediatr 2009:9:289-90.

\section{SAVE TIME AND KEEP INFORMED}

\section{Thorax}

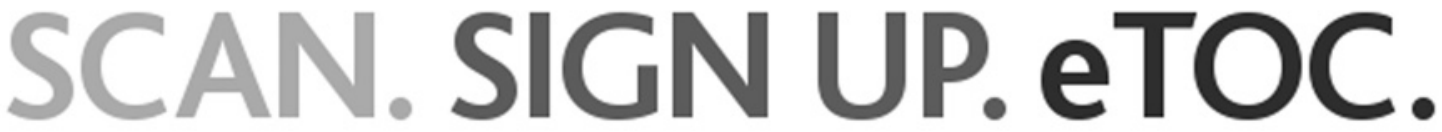

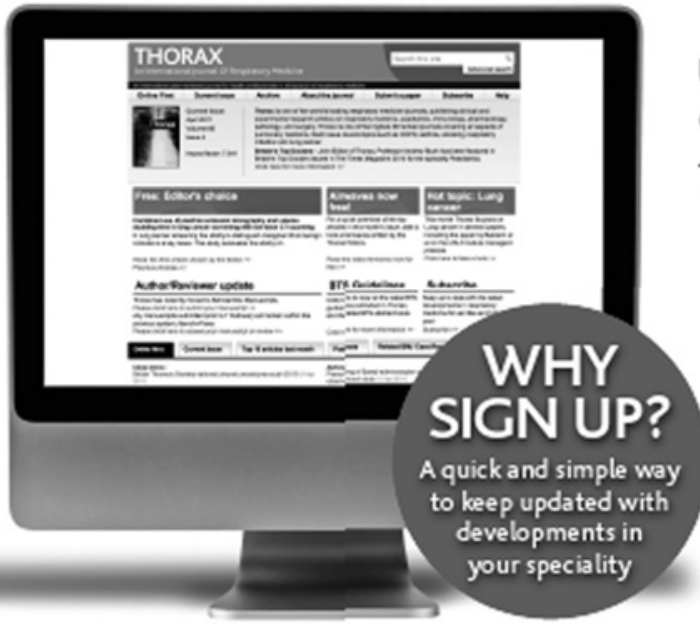

thorax.bmj.com
Utilise our Quick Response code (QR) to sign up for our electronic table of contents (eTOC) alert.

To make this simple you can sign up now via your Smartphone.

\section{FOLLOWTHESE}

THREE EASY STEPS:

1. Downbad a free QR reader from your

handset's app store

2. Hold your Smartphone over the QR code

3. You will then be fonvarded to the $\mathrm{TOC}$ sign up page

To find out more about $Q R$ codes visit

group.bmj.com/products/journals/qr-codes 